\title{
Cardiac Arrest Due to Hypocalcemia
}

Fernanda Aburesi Salvadori, ${ }^{\circledR}$ Eduardo Martelli Moreira, ${ }^{\circledR}$ Murilo Bacchini Dias, ${ }^{1}$ Amaro Nunes Duarte-Neto, ${ }^{2}$ Edison Ferreira de Paiva ${ }^{2}{ }^{\circledR}$

Hospital das Clínicas da Faculdade de Medicina da Universidade de São Paulo, 'São Paulo, Brazil

Faculdade de Medicina da Universidade de São Paulo, ${ }^{2}$ São Paulo, Brazil

Fifty-nine-year-old male patient had a sudden cardiac arrest (CA) while waiting for his appointment at the urology outpatient clinic. The local staff and the rapid response team (RRT) promptly started cardiopulmonary resuscitation maneuvers. Initial CA rhythm was ventricular fibrillation (VF) and the collapseshock interval was five minutes. Return of spontaneous circulation (ROSC) occurred on the following cycle, comprising six minutes of arrest. There was not enough time to administer epinephrine or any other drugs. After ROSC, a definitive airway was placed as the patient remained in a coma. The post-arrest electrocardiogram (ECG) (Figure 1B) did not show signs of acute ischemia, but revealed a prolonged QT interval (corrected QT (cQT), using the Bazett's formula: $558 \mathrm{~ms}$ ) and, for that reason, amiodarone was not administered.

After initial management, it was possible to check patient's history and exams. He had previous diagnosis of Graves' disease, systemic arterial hypertension and polycystic kidney disease, which led to chronic renal insufficiency and hemodialysis. The patient then developed tertiary hyperparathyroidism and, in 2008, was submitted to surgical removal of the parathyroid glands, followed by unsuccessful autotransplantation in the let upper limb, leading to hypoparathyroidism post-parathyroidectomy. For this condition, the patient was given calcitriol and calcium carbonate, both orally

\section{Keywords}

Heart Arrest; Cardiopulmonary Resuscitation; Hypocalcemia; Hypertension; Renal Insufficiency; Tachycardia Ventricular; Renal Dialysis; Kidney Transplantation. and parenterally during hemodialysis sessions. Calcium serum levels were periodically monitored. In May 2019, he underwent kidney transplantation but had urinary tract infection that caused acute dysfunction of the graft. The patient was discharged from the hospital 35 days after the procedure, with serum creatinine level of 7.3 $\mathrm{mg} / \mathrm{dL}$ (reference value [RV]: 0.7 to $1.2 \mathrm{mg} / \mathrm{dL}$ ). The ECG during hospitalization had already revealed a prolonged QT interval (cQT $485 \mathrm{~ms}$ ) (Figure 1A). Three days after hospital discharge, the patient was seen at the medical clinic and had blood samples tested: creatinine level 9.74 $\mathrm{mg} / \mathrm{dL}$; total serum calcium $4.0 \mathrm{mg} / \mathrm{dL}$ (RV: 8.4 to 10.2 $\mathrm{mg} / \mathrm{dL})$; normal serum potassium level $(3.7 \mathrm{mEq} / \mathrm{L} ; \mathrm{RV}$ : 3.5 to $5.0 \mathrm{mEq} / \mathrm{L}$ ). The patient was immediately referred to the Emergency Department for parenteral calcium supplementation and monitoring of kidney function, but left the hospital before medical evaluation. Two weeks after this episode, he returned to the hospital for a previously scheduled appointment in the urology department for follow-up of kidney transplant, reporting progressive weakness, stiffness and cramps, and experienced CA shortly after.

Immediate post-arrest laboratory tests showed serum level of ionized calcium of 1.8 (RV: 4.6 to $5.3 \mathrm{mg} / \mathrm{dL}$ ) and potassium of $3.4 \mathrm{mEq} / \mathrm{L}$. Initial high-sensitive troponin $\mathrm{T}$ was $0.187 \mathrm{ng} / \mathrm{mL}(\mathrm{RV}<0.014 \mathrm{ng} / \mathrm{mL})$, with a peak of $0.242 \mathrm{ng} / \mathrm{mL}$ (in a patient with previous chronic kidney disease). However, transthoracic echocardiogram, showing no wall motion abnormalities, and ECG were not suggestive of myocardial ischemia. Besides, the patient had been submitted to a myocardial perfusion scintigraphy in the year before and there were no signs of stress-induced ischemia. So, given the preCA symptoms, the prolonged QT interval and the

Mailing Address: Fernanda Aburesi Salvadori

Universidade de São Paulo Hospital das Clínicas - Time de Resposta Rápida do Instituto Central

Av. Dr. Enéas Carvalho de Aguiar, 255. Postal Code: 05403-000, São Paulo, SP - Brazil

E-mail: fernanda.salvadori@hc.fm.usp.br 
Table 1 - Serum levels of different electrolytes and its correlation with QT interval in electrocardiograms

\begin{tabular}{|c|c|c|c|c|c|c|}
\hline Event & $\begin{array}{l}\text { ECG (Fig. } \\
\text { 1) }\end{array}$ & $\begin{array}{c}\text { cQT (ms) } \\
\text { (RV:340- } 450 \\
\text { ms) }\end{array}$ & $\begin{array}{c}\text { Ionized calcium } \\
\text { (RV: } 4.6- \\
5.3 \mathrm{mg} / \mathrm{dL} \text { ) }\end{array}$ & $\begin{array}{c}\text { Total calcium } \\
\text { (RV:8.4 - } \\
10.2 \mathrm{mg} / \mathrm{dL})\end{array}$ & $\begin{array}{c}\text { Potassium } \\
\text { (RV:3.5- } \\
5.0 \mathrm{mEq} / \mathrm{L})\end{array}$ & $\begin{array}{c}\text { Creatinine } \\
\text { (RV: 0.7- } \\
1.2 \mathrm{mg} / \mathrm{dL})\end{array}$ \\
\hline $\begin{array}{l}\text { Hospitalization } \\
\text { for kidney } \\
\text { transplant }\end{array}$ & Fig. 1A & 485 & 2.42 & - & 3.8 & 10.51 \\
\hline Post-arrest & Fig. 1B & 588 & 1.8 & 5.2 & 3.4 & 7.14 \\
\hline $\begin{array}{l}\text { Discharge for } \\
\text { cardiac arrest }\end{array}$ & Fig. 1C & 436 & 5.84 & 10.4 & 5.1 & 7.16 \\
\hline
\end{tabular}
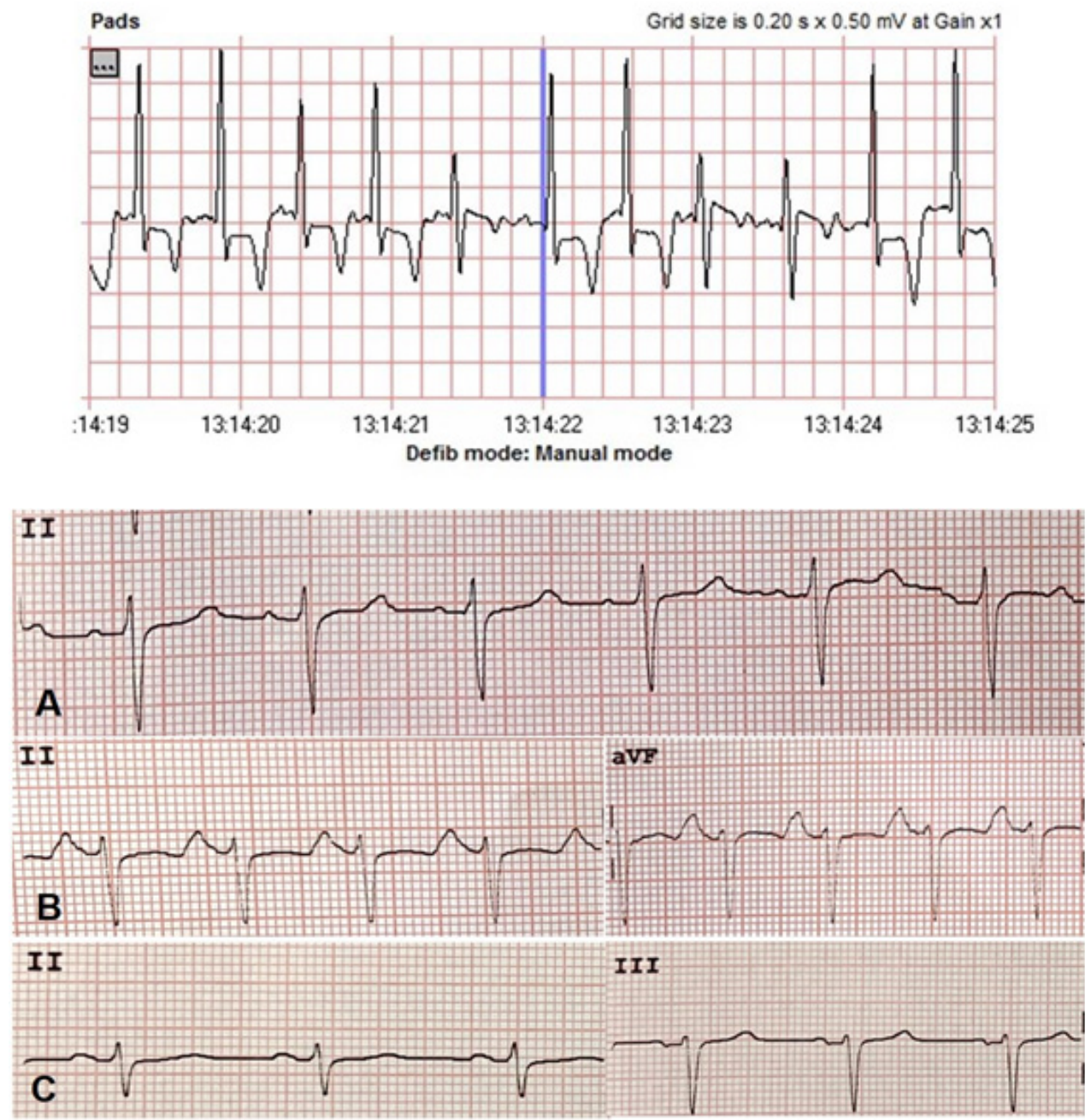

Figure 1 - Segments of electrocardiograms (ECG) showing the progression of the QT interval.

A - ECG during hospitalization for kidney transplant revealing a long QT interval (corrected QT (cQT) using Bazett's formula, of $485 \mathrm{~ms}$ ); B - post-arrest ECG, with cQT of $588 \mathrm{~ms}$; C - ECG after hospital discharge for cardiac arrest, with normal QT interval after calcium supplementation (cQT of $436 \mathrm{~ms}$ ) 
reduced serum ionized calcium level, hypocalcemia was considered the cause of CA, and intravenous calcium gluconate was administered. After restoration of consciousness, the patient informed that he had discontinued the supplementation of oral calcium by his own - parenteral supplementation had been suspended after the transplant, since no more hemodialysis sessions would be performed. During hospitalization, the patient showed favorable neurological recovery, but due to complicated urinary tract infection with unsatisfactory response to antibiotic therapy, the transplanted kidney had to be removed. The ECG at that time exhibited normal QT interval (cQT 436ms) (Figure 1C), with normal calcium serum levels after supplementation (ionized calcium of $5.84 \mathrm{mg} / \mathrm{dL}$ and total calcium of $9.5 \mathrm{mg} / \mathrm{dL}$ ).

\section{Discussion}

Long QT syndrome (LQTS) can be congenital or acquired. The causes of acquired LQTS include hypocalcemia, due to prolongation of the phase 2 of the action potential (AP), ${ }^{1}$ medications (amiodarone, antidepressants and neuroleptics), hypokalemia, hypomagnesemia and severe bradycardia..$^{2-4}$ LQTS is associated with a specific polymorphic ventricular tachycardia (VT), named as torsades de pointes (TdP), because of the characteristic shift in the QRS axis that gives the impression of a "torsion".

The QT interval is a marker of the AP duration. In LQTS patients, the AP is prolonged unevenly across the myocardium, so as to cause high dispersion of repolarization. The AP prolongation favors the formation of early afterdepolarization (EAD), which are deformities in the plateau and rapid repolarization phases (2 and 3) capable of inducing ventricular extrasystoles. EADs in the unevenly repolarized myocardium are the cause of TdP. Tachycardia is sustained due to focal electric activity and/or a reentrant mechanism. It may either cease spontaneously or degenerate into ventricular fibrillation and cardiac arrest ${ }^{3,5}$.

In this report, the CA initial rhythm described - not documented by ECG - was VF. It is possible, however, that the patient experienced a TdP that degenerated to VF, due hypocalcemia-induced LQTS. Amiodarone, which is the first choice of treatment for refractory VF and VT, prolongs QT interval and should be avoided in TdP; lidocaine, on the other hand, has an unclear role in TdP, but could be an alternative in VF/VT due to its effect in reducing the duration of the AP. ${ }^{6}$ The American Heart Association suggests the use of magnesium for treating TdP, but is against its routine use. ${ }^{6,7}$ Calcium gluconate or calcium chloride is indicated for the treatment of hyperkalemia with electrocardiographic manifestations ${ }^{8}$ and for hypocalcemia, with initial bolus followed by continuous infusion, until adequate serum levels are achieved. ${ }^{9}$ In this case, the administration of calcium gluconate probably contributed positively to the favorable outcome.

Cardiac arrest due to hypocalcemia is a rare event that lacks specific recommendations in current literature and guidelines. Hypocalcemia is not part of the differential diagnosis for the causes of CA, known as the " $5 \mathrm{Hs}$ and 5Ts" - "5Hs" refers to hypothermia, hypo/hyperkalemia, hydrogen ion excess (acidosis), hypovolemia and hypoxia; and "5Ts" refers to cardiac tamponade, coronary thrombosis, tension pneumothorax, pulmonary thromboembolism and toxins. ${ }^{7}$ The aim of this report was to suggest that cardiac arrests may have other causes than the ones described in current guidelines, and that it is important to evaluate each patient individually to determine the best possible adjunct treatment. The definite treatment for any CA, however, is the same: early defibrillation when indicated and highquality chest compressions.

\section{Conclusion}

Although hypocalcemia is not among the most common causes of CA, it should be considered for patients with a suggestive history. Guidelines are important to establish standards for the management of patients following CA, but sometimes it is crucial to go beyond standards and individualize strategies for each patient.

\section{Potential Conflict of Interest}

No potential conflict of interest relevant to this article was reported.

\section{Sources of Funding}

There were no external funding sources for this study.

\section{Study Association}

This study is not associated with any thesis or dissertation work.

\section{Ethics Approval and Consent to Participate}

This article does not contain any studies with human participants or animals performed by any of the authors. 


\section{Author Contributions}

Conception and design of the research: Salvadori FA. Acquisition of data: Salvadori FA, Moreira EM, Dias MB. Analysis and interpretation of the data: Salvadori

\section{References}

1. Grandi E, Pasqualini FS, Pes C, Corsi C, Zaza A, Severi S. Theoretical investigation of action potential duration dependence on extracellular Ca2+ in human cardiomyocytes. J Mol Cell Cardiol. 2009;46(3):332-42.

2. Benoit SR, Mendelsohn AB, Nourjah P, Staffa JA, Graham DJ. Risk factors for prolonged QTc among US adults: Third National Health and Nutrition Examination Survey. Eur J Cardiovasc Prev Rehabil. 2005;12(4):363-368.

3. El-Sherif N, Turitto G, Boutjdir M. Acquired Long QT Syndrome and Electrophysiology of Torsade de Pointes. Arrhythm Electrophysiol Rev. 2019;8(2):122-30.

4. Roden DM. Drug-induced prolongation of the QT interval. N Engl J Med. 2004;350(10):1013-22.

5. Weiss JN, Garfinkel A, Karagueuzian HS, Chen PS, Qu Z. Early afterdepolarizations and cardiac arrhythmias. Heart Rhythm. 2010;7(12):1891-9.
FA, Moreira EM, Dias MB. Visualization: Duarte-Neto AN. Writing of the manuscript: Salvadori FA, Moreira EM. Critical revision of the manuscript for intellectual content: Duarte-Neto AN, Paiva EF.

6. Panchal AR, Berg KM, Hirsch KG, Kudenchuk PJ, Rios MD, Cabañas JG, et al. 2019 American Heart Association Focused Update on Advanced Cardiovascular Life Support: use of advanced airways, vasopressors, and extracorporeal cardiopulmonary resuscitation during cardiac arrest: an update to the American Heart Association Guidelines for Cardiopulmonary Resuscitation and Emergency Cardiovascular Care. Circulation. 2019;140(24):e881-94.

7. Panchal AR, Berg KM, Kudenchuk PJ, Rios MD, Hirsch KG, Link MS, et al. 2018 American Heart Association Focused Update on Advanced Cardiovascular Life Support Use of Antiarrhythmic Drugs During and Immediately After Cardiac Arrest: an update to the American Heart Association Guidelines for Cardiopulmonary Resuscitation and Emergency Cardiovascular Care. Circulation. 2018;138(23):e740-9.

8. Weisberg LS. Management of severe hyperkalemia. Crit Care Med. 2008;36(12):3246-51.

9. Kelly A, Levine MA. Hypocalcemia in the critically Ill patient. J Intensive Care Med. 2013;28(3):166-77. 